Review Article

\title{
COVID-19: An Updated Situation from Singapore
}

\author{
Ke-Yan Loo', Angel Yun-Kuan Thye', Lydia Ngiik-Shiew Law ${ }^{2}$, Jodi Woan-Fei Law ${ }^{1 *}$ \\ Article History \\ Received: 30 September \\ 2021; \\ Received in Revised Form:

\begin{abstract}
${ }^{1}$ Novel Bacteria and Drug Discovery Research Group (NBDD), Microbiome and Bioresource Research Strength (MBRS), Jeffrey Cheah School of Medicine and Health Sciences, Monash University Malaysia, Subang Jaya 47500, Malaysia; $\quad$ ke.loo@monash.edu (K-YL); angelthye.yunkuan@monash.edu (AY-KT)
\end{abstract}

30 October 2021;

Accepted: 1 November 2021;

Available Online: 9

November 2021
${ }^{2}$ Monash Credentialed Pharmacy Clinical Educator, Faculty of Pharmacy and Pharmaceutical Sciences, Monash University, 381 Royal Parade, Parkville 3052, VIC, Australia; lydia19595@gmail.com (LN-SL)

*Corresponding author: Jodi Woan-Fei Law; ${ }^{1}$ Novel Bacteria and Drug Discovery Research Group (NBDD), Microbiome and Bioresource Research Strength (MBRS), Jeffrey Cheah School of Medicine and Health Sciences, Monash University Malaysia, Subang Jaya 47500, Malaysia; jodi.law1@monash.edu (JW-FL)

\begin{abstract}
Since the first reports of COVID-19 in 2019, the viral respiratory disease has spread across nations, sending the world into a global pandemic. The pandemic has heavily impacted the public health of the global community. Over 237 million confirmed cases have been reported, and more than 4.8 million lives have been lost due to the novel coronavirus. In Singapore, the government quickly took action in the early stages of the pandemic to limit the spread of the virus to protect the local communities from the disease. Singapore has been able to keep their confirmed COVID-19 cases and deaths at low numbers by implementing movement restrictions, raising public awareness, mask mandates, social distancing, providing free vaccinations for the public, and utilizing advancements in technology for contact tracing. The public has also upheld their social responsibility in cooperating with the Singaporean government to control the disease spread. COVID-19 is now moving into an endemic phase in Singapore as the vaccination rates are at an all-time high resulting in lower death rates, and the confirmed cases are primarily mild to asymptomatic. Singapore has set a precedent for how pandemics can be handled in the future to minimize mortality rates and protect public health.
\end{abstract}

Keywords: COVID-19; SARS-CoV-2; coronavirus; endemic; Singapore

\section{Introduction}

Two years have passed since discovering the novel coronavirus, SARS-CoV-2, which causes COVID-19, a highly contagious respiratory disease that sent the world into a global pandemic. The virus has since spread across countries across the globe, upending the livelihoods of many worldwide ${ }^{[1-4]}$. To date, more than 237 million confirmed cases have been documented globally, and the virus has claimed more than 4.8 million lives ${ }^{[5]}$. COVID19 spread at an alarming rate from China to other countries within a short period. The severity of the disease led the World Health Organization to declare COVID-19 as a global pandemic 
in March $2020^{[6]}$. The severity and fatality of the viral illness prompted the development of vaccines at lightning speed, and finally, in December 2020, vaccines effective in controlling COVID-19 were available for use. At the time of writing, over 6.3 billion individuals worldwide have received at least one dose of the COVID-19 vaccines ${ }^{[5]}$. In the early stages of the pandemic, there were no cures or vaccines that could effectively treat and prevent the transmission of the coronavirus across national borders ${ }^{[7]}$. Thus, leaders of countries such as Singapore, China, Japan, South Korea, and Taiwan acted quickly and implemented safety measures to prevent the rampant spread of the disease. These countries closed their borders, upscaled the production of face masks and COVID-19 test kits, increased illness testing, and enforced mask mandates to protect their civilians ${ }^{[8]}$.

Singapore, a sunny tropical country in Southeast Asia with a population of 5.7 million, has often been cited as exemplary for other countries in handling the COVID-19 pandemic ${ }^{[9,10]}$. Singapore has been able to control the spread of the virus within the country, with the total number of confirmed cases sitting at 187,851 cases, while 364 deaths have been reported as of October 28, 2021. These numbers are significantly lower when compared to other first-world countries ${ }^{[11]}$. The Singaporean government quickly developed a successful framework to manage disease outbreaks earlier on in the pandemic. The government enforced stringent measures necessary to protect the people from the virus by implementing a national lockdown, extensive testing, contact tracing, mask mandates, social distancing, and raising awareness for COVID-19 among the public ${ }^{[12]}$.

\section{COVID-19 Situation in Singapore}

The first incidence of COVID-19 in Singapore was an imported case involving a 66year-old Chinese national on January $23,2020^{[13]}$. The public was still at ease until a local transmission was reported in early February, which set the whole nation on high alert. Singapore then raised its national assessment level, the Disease Outbreak Response System Condition (DORSCON) level from "yellow" to "orange" to alert the public of a possible local pandemic. During this time, the daily number of confirmed cases in Singapore was still less than 10 cases a day. In Singapore, technological advancements were greatly utilized to handle the pandemic. The Government Technology of Singapore (GovTech) had already developed a mobile phone-based tracing application known as TraceTogether once confirmed cases were reported in the country. TraceTogether was launched in March 2020 to track the interactions between those diagnosed with the coronavirus and their close contacts. Those who may have contracted the virus unknowingly from the community could be traced and put under quarantine to prevent further dissemination of the virus. An "exposure notification" would be provided to affected individuals to protect public health. Moreover, the source code for TraceTogether is open, so any country that wishes to develop its contact tracing app quickly could do so based on TraceTogether's development ${ }^{[14]}$.

However, a surge in cases was reported in March due to Singaporeans returning from abroad, followed by a massive outbreak in the foreign workers' dormitories (Figure 1). The cases increased from 102 cases a day at the end of February to more than 1000 cases a day in early April. The situation was further exacerbated by the rapidly increasing number of new 
and unlinked cases within the community. Thus, a "circuit breaker" was implemented with a stringent set of lockdown measures from April 7 to June 1 to better control the spread of the infection. Schools and non-essential services were closed during the circuit breaker, and visitations or gatherings with family members or friends who did not reside together were prohibited.

Furthermore, the government also introduced SafeEntry, a national free-to-use cloudbased visitor registration system that $\operatorname{logs}$ individuals' visits to businesses or venues providing essential services. Before entering the premises, individuals are required to provide personal information such as their name, National Registration Identity Card (NRIC) number, and mobile phone number. They could do so by scanning the SafeEntry Quick Response (QR) code, commonly displayed at the entrance of businesses or premises. They are also required to log the time when they leave the premises within the system. Over 40,000 locations in the country have utilized SafeEntry for contact tracing purposes, enabling the officials to quickly track down possible outbreak clusters and close contacts of infected persons ${ }^{[15]}$. The circuit breaker successfully reduced the daily number of confirmed cases, resulting in the resumption of economic and community activities in phases with less strict rules. In May 2021, breathalyzers used to detect COVID-19 which gives accurate results within 1-2 minutes were provisionally approved for use in Singapore ${ }^{[16]}$. The breathalyzers were developed locally by the National University of Singapore's spin-off start-up Breathonix (BreFence Go COVID-19 Breath Test System) and Silver Factory Technology (TracieX Beathalyser). Every exhalation contains thousands of volatile organic compounds (VOC), which can indicate the presence of different diseases or infections in the host. When an individual breathes into the breathalyzer, the exhaled air is collected and analyzed by a portable reader, which results within two minutes ${ }^{[17,18]}$. BreFence Go utilizes mass spectrometry while Raman spectrometry is used in TracieX to analyze the VOC. Moreover, BreFence Go has a sensitivity of $85.3 \%$ and a specificity of $97 \%$, while TracieX has a sensitivity of $95 \%$ with a specificity of $97.8 \%$ in identifying the VOC in individuals with COVID-19 ${ }^{[16]}$. The breathalyzers are cost-effective screening options for COVID-19 as they are relatively inexpensive (SGD5-SGD20 per device) and can deliver results at high specificity and sensitivity ${ }^{[19]}$.

After June 1, Singapore was in Phase 1 of reopening, whereby some activities beyond essential services were allowed to reopen. Phase 2 of reopening commenced shortly after that on June 17, and the public was allowed to dine-in at restaurants with a 5-person limit, and retail operations were able to resume. Six months later, Phase 3 of reopening commenced with the limitation of public gatherings and home visitations increased from 5 to 8 people. Free vaccinations were also introduced to all Singaporeans and long-term residents. The priority would be given to healthcare and frontline workers, followed by the elderly aged 70 and above ${ }^{[12]}$. 


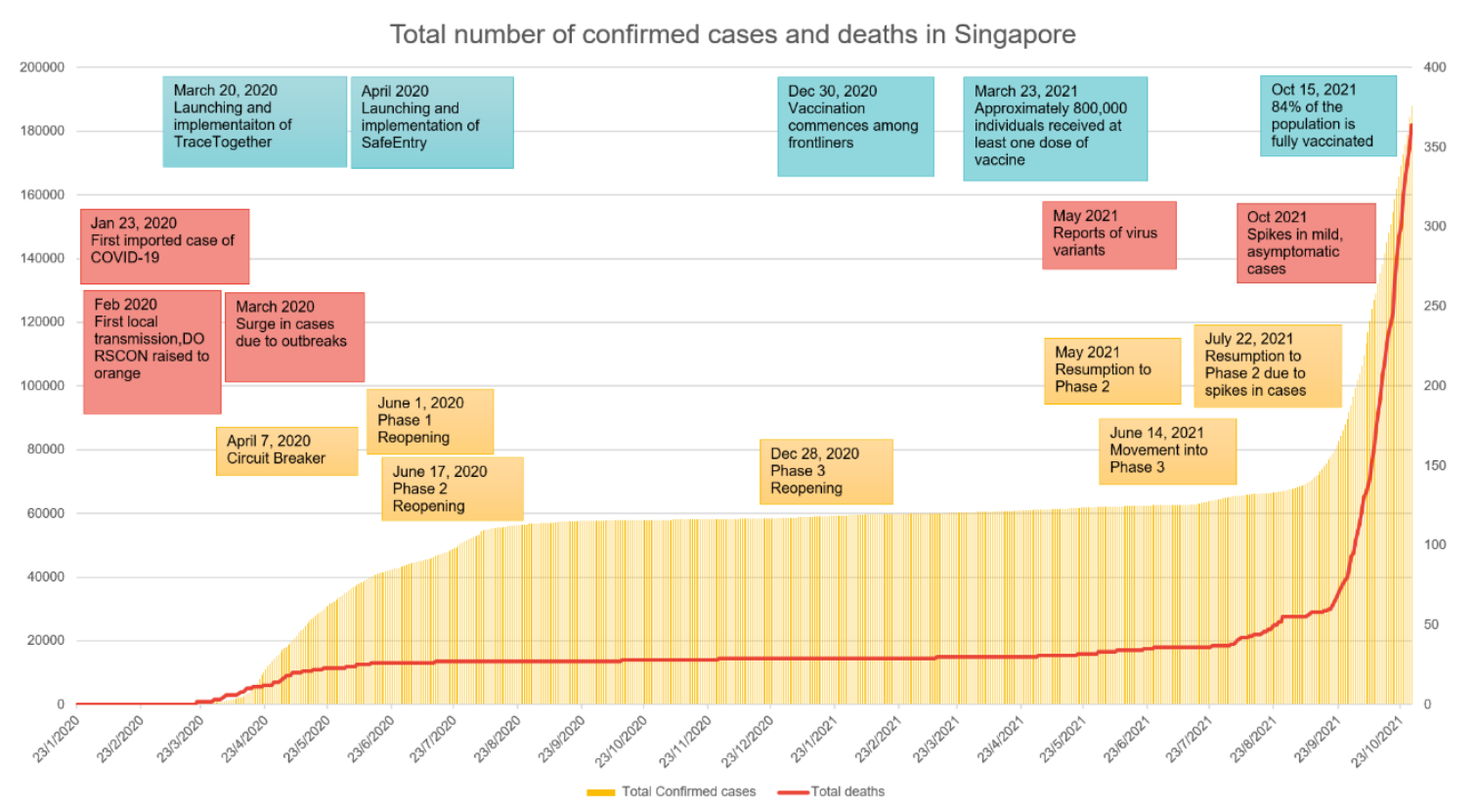

Figure 1. Total number of confirmed cases and deaths in Singapore.

In 2021, travelers or Singaporeans from abroad were required to take a polymerase chain reaction (PCR) test to detect the COVID-19 infection upon arrival in Singapore as an effort to prevent the spread of the virus from imported cases. An extra 7-day self-isolation is also mandatory for those who have traveled from the United Kingdom and South Africa in addition to their 14-day Stay Home Notice (SHN) at dedicated facilities ${ }^{[20]}$. The number of daily confirmed cases was decreasing. Henceforth by late March, the Singapore Ministry of Health $(\mathrm{MOH})$ announced that from April 5, 2021, onwards, more employees would be allowed to return to their workplaces to boost the central business district and the industrial park sector ${ }^{[21]}$. Mass vaccination had begun at this time, and approximately 800,000 individuals had received at least one dose of the vaccine, and the vaccination program was set to roll out to younger age groups ${ }^{[21]}$. Currently, the Pfizer-BioNTech (Comirnaty) and Moderna COVID-19 vaccines are authorized for use by the Health Sciences Authority in Singapore under the Pandemic Special Access Route (PSAR). Both of these vaccines are mRNA vaccines, and they have been found to be effective against various variants of the SARS-CoV-2 coronavirus ${ }^{[22-24]}$. These vaccines work by delivering mRNA to the host cells to make copies of the spike proteins of SARS-CoV-2. The host immune system recognizes these spike proteins and elicits an immune response, ultimately activating memory B cells for adaptive immunity. In the event of future exposure to the actual virus, the host immune system will be able to recognize the virus, and immune responses will be triggered to fight against $\mathrm{it}^{[24]}$. In May 2021, there was an increase in reports of dangerous variants of the coronavirus worldwide ${ }^{[25-27]}$ and the detection of several clusters of infection within the community in Singapore. These situations prompted the Singaporean government to revert to Phase 2 (Heightened Alert) to prevent the spread of these variants and avoid enforcing another circuit breaker that could be detrimental to the economy and negatively affect the citizens $^{[28]}$. As vaccination rates continued to rise to achieve herd immunity in Singapore, the Pfizer-BioNTech COVID-19 vaccine was authorized for use in those aged 12 to 15 on May 
$18^{[29]}$. Once herd immunity is achieved, working from home and home-based learning would cease. At the same time, contact tracing and border restrictions will be retained to hinder the dissemination of dangerous variants of the virus into the country ${ }^{[30]}$. In June $2021, \mathrm{MOH}$ announced the movement into Phase 3 in two steps on June 14, with the increase in the limit for social gathering and distinct visitors allowed per household and the possibility of more restrictions lifted on June $21^{[31]}$. Nevertheless, with the cases spike again shortly after the announcement, Singapore was again in Phase 2 from July 22 to August $18^{[32]}$. The Singaporean government then gave out DIY antigen rapid test (ART) kits to every household in Singapore and pre-school staff and students to encourage more COVID-19 testing within the community. These initiatives gave the public the social responsibility in making Singapore a COVID-19 resilient nation ${ }^{[33]}$. Throughout the fight against the pandemic, the Singaporean government has been consistently transparent in updating the public on the COVID-19 situation in the country through the MOH's website. The latest restrictions and safety measures are constantly posted to remind the public to stay safe and protect themselves during these trying times ${ }^{[34]}$. Social media platforms such as Whatsapp, Twitter, Telegram, and Facebook were used to inform the public on the latest updates of COVID-19 in Singapore and circulate information on reducing the risk of infections ${ }^{[13]}$.

At the time of writing, the daily number of confirmed cases in Singapore has steadily increased to over 3500 cases a day. Interestingly enough, $84 \%$ of the residents in Singapore have already been fully vaccinated against COVID-19 ${ }^{[11]}$. The driving force for the increase in cases is likely due to the government's four-step strategy announced in August, where the focus would be put on higher vaccinations and severe cases of infections. The government aims to see COVID-19 as endemic and for the people to carry on with their lives as the virus remains in the community ${ }^{[35]}$. Rules and restrictions have begun to loosen for those fully vaccinated, allowing the residents to move forward to a new normal in their lives. In addition, the presence of the more infectious delta variant of the coronavirus in Singapore also contributes to the spike in confirmed cases ${ }^{[36]}$. Currently, over $98 \%$ of the reported cases had mild to no symptoms, while only $1.1 \%$ of cases require oxygen supplementation, and $0.1 \%$ of cases require intensive care ${ }^{[34]}$. The government is not overly fixated on the increasing daily number of confirmed cases due to its mild nature. They remain optimistic about the situation in Singapore as serious infections are rising at a slower rate ${ }^{[36]}$. Although high vaccination rates can minimize the effects of the disease, non-pharmacological interventions such as mask-wearing and social distancing should not be abandoned as the population remains vulnerable to the airborne virus, especially in the presence of dangerous variants ${ }^{[37]}$. Testing for the virus should also be continuously upheld within the community to detect any infections earlier on to prevent outbreaks and protect individuals who are more susceptible to the illness, such as those who are ineligible for the vaccines. These efforts could also prevent the healthcare system from becoming overwhelmed and ensure that COVID-19 and non-COVID-19 patients would still receive timely care from healthcare professionals. 


\section{Conclusion}

The cooperation between the local government and the public, which upholds their social responsibility, has successfully controlled the COVID-19 pandemic in Singapore. High vaccination rates resulting in significantly lower COVID-related death rates, coupled with the majority of confirmed cases being mild or asymptomatic in the country, the disease is moving towards an endemic phase in Singapore. The governance, transparency, utilization of technological advancements, and enforcement of social responsibility in tackling the pandemic in Singapore set a good precedent for other countries that aim to achieve a new normal with COVID-19.

Author Contributions: K-YL performed the literature search, critical data analysis, and manuscript writing. AY-KT and LN-SL performed proofreading and editing. JW-FL conceptualized this review writing project.

Funding: No external funding was provided for this research.

Acknowledgments: The authors would like to acknowledge Professor Shajahan Yasin, Head of School, Jeffrey Cheah School of Medicine and Health Sciences, Monash University Malaysia

Conflicts of Interest: The authors declare no conflict of interest.

\section{References}

1. Ser H-L, Letchumanan V, Law JW-F, et al. PMMB COVID-19 Bulletin: Spain (18th April 2020). Prog Microbes Mol Bio 2020; 3(1).

2. Tan LT-H, Letchumanan V, Ser H-L, et al. PMMB COVID-19 Bulletin: United Kingdom (22nd April 2020). Prog Microbes Mol Bio 2020; 3(1).

3. Loo K-Y, Letchumanan V. COVID-19: Malaysia's fight against this deadly virus. Prog Microbes Mol Bio 2021; 4(1).

4. Johnson D, Ren SEC, Johnson HD, et al. COVID-19: Are Malaysians embracing or suffering the new normality? Prog Microbes Mol Bio 2020; 3(1).

5. World Health Organization (WHO). WHO Coronavirus (COVID-19) Dashboard. 2021 [Accessed 2021 Oct 10]; Available from: https://covid19.who.int/.

6. World Health Organization (WHO). WHO Timeline - COVID-19. 2020 [Accessed 2021 Oct 12]; Available from: https://www.who.int/news/item/27-04-2020-who-timeline---covid-19.

7. Letchumanan V, Ab Mutalib N-S, Goh B-H, et al. Novel coronavirus 2019-nCoV: could this virus become a possible global pandemic. Prog Microbes Mol Bio 2020; 3(1).

8. Lu N, Cheng K-W, Qamar N, et al. Weathering COVID-19 storm: successful control measures of five Asian countries. Am J Infect Control 2020; 48(7): 851-852.

9. Kuguyo O, Kengne AP, and Dandara C. Singapore COVID-19 pandemic response as a successful model framework for low-resource health care settings in Africa? OMICS 2020; 24(8): 470-478.

10. Abdou AM. Good governance and COVID-19: The digital bureaucracy to response the pandemic (Singapore as a model). J Public Aff 2021: e2656.

11. Ritchie H, Mathieu E, Rodés-Guirao L, et al. Coronavirus Pandemic (COVID-19). 2020; Available from: https://ourworldindata.org/coronavirus.

12. Tan OS, Chua JJE. Science, social responsibility, and education: the experience of singapore during the COVID-19 pandemic, in primary and secondary education during Covid-19. 2022, Springer. p. 263-281. 
13. Wong JEL, Leo YS, Tan CC. COVID-19 in Singapore-current experience: critical global issues that require attention and action. JAMA 2020; 323(13): 1243-1244.

14. Lee T, Lee H. Tracing surveillance and auto-regulation in Singapore: 'smart' responses to COVID-19. Media Int Aust 2020; 177(1): 47-60.

15. Lai SHS, Tang CQY, Kurup A, et al. The experience of contact tracing in Singapore in the control of COVID-19: highlighting the use of digital technology. Int Orthop 2021; 45(1): 65-69.

16. Health Sciences Authority. HSA grants provisional authorisation for 'Brefence Go COVID-19 Breath Test System' and 'TracieX Breathalyser' for detection of COVID-19 infection. 2021 [Accessed 2021 Oct 20]; Available from: https://www.hsa.gov.sg/announcements/regulatory-updates/hsa-grantsprovisional-authorisation-for-brefence-go-covid-19-breath-test-system-and-traciex-breathalyser-fordetection-of-covid-19-infection.

17. National Centre for Infectious Diseases. COVID-19 breathlysers could be used on large scale in S'pore soon. 2021 [Accessed 2021 Oct 23]; Available from: https://www.ncid.sg/NewsEvents/News/Pages/COVID-19-breathalysers-could-be-used-on-large-scale-in-S\%27pore-soon.aspx.

18. Malaysia Health Technology Assessment Section (MaHTAS). COVID-19 breathanalyser screening tools. 2020: Malaysia.

19. Wallbank D. Singapore approves Covid breath test with one-minute result. 2021 [Accessed 2021 Oct 20]; Available from: https://www.thestar.com.my/tech/tech-news/2021/05/24/singapore-approvescovid-breath-test-with-one-minute-result.

20. Channel News Asia (CNA). All travellers, including Singaporeans, to take COVID-19 test upon arrival in Singapore. 2021 [Accessed 2021 Oct 12]; Available from: https://www.channelnewsasia.com/singapore/covid-19-test-travellers-singaporeans-border-measuresmoh-411966.

21. Ministry of Health Singapore (MOH). Expansion of vaccination programme; further easing of community measures. 2021 [Accessed 2021 Oct 12]; Available from: https://www.moh.gov.sg/news-highlights/details/expansion-of-vaccination-programme-furthereasing-of-community-measures.

22. Ministry of Health Singapore (MOH). Vaccination information sheet: Moderna COVID-19 vaccine. 2021: Singapore.

23. Ministry of Health Singapore (MOH). Vaccination information sheet: Pfizer-BioNTech/Comirnaty COVID-19 vaccine. 2021: Singapore.

24. Loo K-Y, Letchumanan V, Ser H-L, et al. COVID-19: insights into potential vaccines. Microorganisms 2021; 9(3): 605.

25. World Health Organization (WHO). Tracking SARS-CoV-2 variants. 2021 [Accessed 2021 Oct 12]; Available from: https://www.who.int/en/activities/tracking-SARS-CoV-2-variants/.

26. Ser H-L, Tan LT-H, Law JW-F, et al. Genomic analysis of severe acute respiratory syndrome coronavirus 2 (SARS-CoV-2) strains isolated in Malaysia. Prog Microbes Mol Bio 2020; 3(1).

27. Thye AY-K, Law JW-F, Pusparajah P, et al. Emerging SARS-CoV-2 variants of concern (VOCs): an impending global crisis. Biomed 2021; 9(10): 1303.

28. Ministry of Health Singapore (MOH). Updates on local situation and heightened alert to minimise transmission. 2021 [Accessed 2021 Oct 12]. 
29. Ministry of Health Singapore (MOH). Progress of and adjustment to vaccination programme and updated guidance on use of masks. 2021 [Accessed 2021 Oct 12]; Available from: https://www.moh.gov.sg/news-highlights/details/progress-of-and-adjustments-to-vaccinationprogramme-and-updated-guidance-on-use-of-masks.

30. Lim YL. Singapore planning for a new normal of living with Covid-19: PM Lee, in The Straits Times. 2021.

31. Abu Baker J. Up to 5 in a group allowed from Jun 14; dining-in may resume on Jun 21 in phased easing of COVID-19 curbs. 2021 [Accessed 2021 Oct 12]; Available from: https://www.channelnewsasia.com/singapore/cap-of-5-people-social-gatherings-dining-in-phase-3covid-19-1846791.

32. Ministry of Health Singapore (MOH). Going back to phase 2 heightened alert. 2021 [Accessed 2021 Oct 12]; Available from: https://www.moh.gov.sg/news-highlights/details/going-back-to-phase-2heightened-alert.

33. Tjendro J. All households to receive six COVID-19 self-test kits via mail from Aug 28. 2021 [Accessed 2021 Oct 12]; Available from: https://www.channelnewsasia.com/singapore/covid-19antigen-rapid-test-kits-households-pre-schools-primary-schools-moh-2139756.

34. Ministry of Health Singapore (MOH). Update on local COVID-19 situation (15 Oct 2021). 2021 [Accessed 2021 Oct 15]; Available from: https://www.moh.gov.sg/news-highlights/details/update-onlocal-covid-19-situation-(15-oct-2021).

35. Kapur M. Singapore's rising Covid cases offer a glimpse into what it means to live with the virus. 2021 [Accessed 2021 Oct 12]; Available from: https://qz.com/india/2068834/highly-vaccinatedsingapore-sees-rising-covid-cases/.

36. Goh T. Covid-19 cases in S'pore rising faster than expected, but serious infections rising at slower rate, in The Straits Time. 2021: Singapore.

37. Fukutani KF, Barreto ML, Andrade BB, et al. Correlation between SARS-Cov-2 vaccination, COVID19 incidence and mortality: tracking the effect of vaccination on population protection in real time. Front Genet 2021; 12(892).

Author(s) shall retain the copyright of their work and grant the Journal/Publisher right for the first publication with the work simultaneously licensed under:

Creative Commons Attribution-NonCommercial 4.0 International (CC BY-NC 4.0). This license allows for the copying, distribution and transmission of the work, provided the correct attribution of the original creator is stated. Adaptation and remixing are also permitted. 